\title{
Urgences
}

\section{Fantaisie sur... la chance}

\section{Marielle Sénéchal}

Numéro 7, 2e trimestre 1983

URI : https://id.erudit.org/iderudit/025105ar

DOI : https://doi.org/10.7202/025105ar

Aller au sommaire du numéro

Éditeur(s)

Urgences

ISSN

0226-9554 (imprimé)

1927-3924 (numérique)

Découvrir la revue

Citer ce document

Sénéchal, M. (1983). Fantaisie sur... la chance. Urgences, (7), 51-56.

https://doi.org/10.7202/025105ar

Ce document est protégé par la loi sur le droit d'auteur. L’utilisation des services d'Érudit (y compris la reproduction) est assujettie à sa politique d'utilisation que vous pouvez consulter en ligne.

https://apropos.erudit.org/fr/usagers/politique-dutilisation/
Cet article est diffusé et préservé par Érudit.

Érudit est un consortium interuniversitaire sans but lucratif composé de l’Université de Montréal, l'Université Laval et l'Université du Québec à Montréal. Il a pour mission la promotion et la valorisation de la recherche. https://www.erudit.org/fr/ 



\section{FANTAISIE SUR... LA CHANCE}

Je pense au prophète Élie qui se baladait sur un "char de feu" au neuvième siècle avant J.C....

Cela donne du panache, non?

Mille ans après lui, le pauvre saint Paul

se déplaçait sur un vieux cheval nerveux...

(... et puis, avouez que ça vous en ficherait un coup si votre voisin d'en face stationnait un tel engin devant sa porte...)

Mais tout célèbre qu'il eût été,

Élie dut prendre sa retraite un jour.

Eh bien, croyez-le ou non, c'est le grand Isaïe lui-même

qui I'a installé au très sélect club "L'Ancien"

où I'on peut selon son humeur

jouer de la flûte ou faire de la poésie...

(... ça vaut bien le Sénat, ma foi!...)

On lui a cependant demandé

de garer son véhicule

dans un souterrain

de la jolie ville de Jéricho. 
II a laissé le manuel de pilotage

(... oh!... pas très en vue...)

et un journal de bord

que les usagers devraient tenir

sous peine d'être transformés en statues.

(Vieux cachottier, va! Dire qu'il a fallu un millénaire pour que la Chananéenne découvre l'astronef... qui est toujours là d'ailleurs. Je l'ai vu lors de mes dernières vacances et n'importe quel touriste pouvait lire le journal de bord...)

“An 67. - Quand j'ai vu l'objet, je l'ai épousseté et j'ai tout de suite pensé au prophète. Une intuition, comme ça. Et puis... l'émotion sans doute... je me suis endormie... et réveillée aussitôt devant une grande porte qui s'ouvrait. Des hauts dignitaires accueillaient et consolaient Paul de Tarse qui venait d'être assassiné. On a sans doute cru que j'étais sa servante, je suis passée sans avoir à montrer mes papiers. Et je lui tiens compagnie."

\section{(... Lui qui aimait l'écriture!...)}

“An 68. - On a confié à Paul des responsabilités et les clés d'or qui les accompagnent. Mais il reste emmuré dans sa peine d'être tenu à l'écart des Douze.

Je lui ferai un pain.

En attendant qu'il me voie, j'apprends la navigation spatiale." 
(... pour une ramasseuse de miettes...)

"An 70. - J'ai survolé notre pays de la pointe de la Galilée jusqu'à Massada. II ne reste qu'un mur du Temple et les Romains vont tuer jusqu'au dernier Juif.

Je rentre

pour faire un immense pain.

Paul connaît les réserves,

il m'entendra

et me donnera une clé

en échange du manuel de pilotage

de l'astronef d'un prophète chanceux."

(!!!...???... le 15 février 1983...) 


\section{PÉRORAISON}

Vous savez, le prince...

il dort chez moi cette nuit

avec sa petite fille.

Comment ai-je pu me retrouver dans une situation pareille alors que je ne possède qu'un vieil oreiller!

Aurais-je quelque chose en commun avec le prince? peut-être... je trouverai...

II partage avec l'enfant l'oreiller de grand'mère qui pique un peu à cause des petites plumes entêtées à traverser le coutil, le couvre-oreiller et la taie.

Pourquoi ai-je tant de fois retardé la corvée de le réparer! ah oui! c'est à cause des plumes

qui s'envoleraient comme de vraies folles.

Non, M. Socrate, ne le dérangez pas!

$\mathrm{J}$ 'adore les enfants et je trouve la scène charmante.

Pliez votre bonnet de nuit et retournez au dictionnaire.

A votre époque, dans toutes les prémisses, il manquait un... chut... le prince va parler... 
"Seigneur, comme ces journalistes interprètent mes paroles! Moi, je mettrais mes pas dans ceux de sir Wilfrid?
Allons donc!...
Non, il restait cette petite qui n'avait pas fait son tour du monde.
Quand elle saura marcher sur un tapis rouge
car il y a la manière, voyez-vous...
comme prévoir des semelles de cuir
lever le pied juste ce qu'il faut
et constater vite à quel émir appartient la main qui avance.
Quand elle saura, dis-je,
alors là, j'apprendrai le nom des oiseaux."
Et moi, je vais recouvrir cet oreiller
avec du tissu moderne
et oublier le vieux en dessous.
Comme ça je n'aurai pas d'ennuis avec les plumes! 